\title{
Un lugar en el campo literario: Marvel Moreno como la "escritora reservada"
}

\author{
Mercedes Ortega González-Rubio' (iD 0000-0002-3682-6918 \\ 2Universidad del Norte, Barranquilla, Atlantico, Colombia. 081007 - humanidades- \\ filosofía@uninorte.edu.co
}

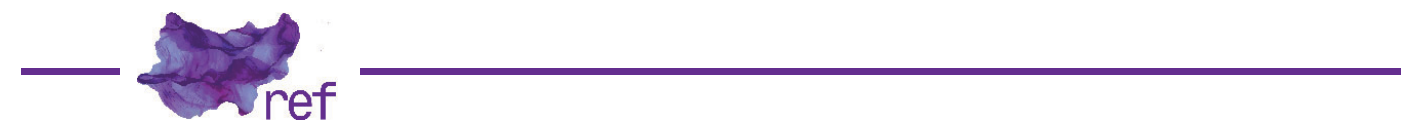

Resumen: El artículo indaga en la figura autorial de la colombiana Marvel Moreno, que se construye alrededor de su inadecuación en el canon literario caribeño colombiano y latinoamericano. Esta marginación sienta gran parte de sus bases en el hecho de ser una escritora en un campo mayoritariamente masculino y sin duda alguna masculinista. Tal posición juega un doble papel pues, al mismo tiempo que pretende darle un lugar propio en el campo, la excluye de él hasta el punto de invisibilizarla. Primero se analizarán las voces presentes en su narrativa, aspecto que se halla relacionado con el posicionamiento de la obra y de la autora en el campo literario. Seguidamente, nos centraremos en algunos textos críticos sobre la autora y su obra para observar cómo su imagen corresponde a ciertas figuras del imaginario propio de la escritora: Judith Shakespeare, la artista maldita, la hermana menor, entre otras. Finalmente se verá si la inclusión de una escritora como Marvel Moreno en el campo literario colombiano sigue siendo aún hoy problemática.

Palabras-clave: Marvel Moreno; feminismo; escritura de mujeres; literatura colombiana; estudios autoriales.

\begin{abstract}
A place in the literary field: Marvel Moreno as the "reserved writer"
Abstract: This article looks into the authorial figure of Colombian writer Marvel Moreno which is constructed around her inadequacy in the literary canon of the Colombian Caribbean and Latin America. This marginalization is rooted in the fact that she was a female writer in a male and masculinist dominated field. This position plays a double edge sword as it gives her own place in the field, but at the same time it excludes her from it to such an extent that she becomes invisible. First, we analyze the voices within her texts, which are related to her posture in the literary field. Then we focus on some critical texts about the author and her work to discern if her image corresponds to certain female figures of the writer's imaginary such as: Judith Shakespeare, the 'poète maudit' or cursed poet, the little sister, and so on. Finally, we will see if the inclusion of a woman writer as Marvel Moreno in the Colombian literary field still is a problem nowadays.
\end{abstract}

Keywords: Marvel Moreno; Feminism; Women's Writing; Colombian Literature; Authorial Studies.

\section{Um lugar no campo literário: Marvel Moreno como a "escritora reservada"}

Resumo: Este artigo indaga acerca da figura autoral da colombiana Marvel Moreno, construída em torno a sua inadequação no cânone literário do Caribe colombiano e latino-americano. Essa marginação está estabelecida em grande parte sobre o fato de ela ser uma escritora dentro de um campo majoritariamente masculino e sem dúvida masculinista. Essa posição tem um duplo efeito, pois ao mesmo tempo que pretende oferecer a Moreno um lugar próprio dentro do campo literário também logra excluí-la desse campo, até torná-la invisível. Primeiramente, considerarei as vozes presentes na narrativa de Moreno, as quais se relacionam com posicionamento da autora e da sua obra no campo literário. Em seguida, analisarei alguns textos críticos sobre a autora e sua obra para observar se sua imagem pode corresponder a certas figuras do imaginário próprio da escritora: Judith Shakespeare, a artista maldita, a irmã mais nova, entre outras. Finalmente, tentarei mostrar se a inclusão de uma escritora como Marvel Moreno no campo literário colombiano ainda é um problema.

Palavras-chave: Marvel Moreno; feminismo; escrita das mulheres; literatura colombiana; estudos autorais. 
Devenir autor es un proceso que no tiene lugar en la habitación propia, aislada, de la escritura, sino en la escena social y políitica, una escena en la cual la autorialidad depende de la mirada ajena y, por tanto, de la institución de una imagen reconocible y doblemente impropia: construida mediante relatos colectivos, y vulnerable a las múltiples reelaboraciones y reescrituras de los agentes del campo cultural. (Aina PÉREZ; Meri TORRAS; Eleonora CRÓQUER, 2015, p. 24)

Marvel Moreno (Barranquilla, 1939 - París, 1995) es la escritora de mayor relevancia en el ámbito del Caribe colombiano y entre las más representativas de la literatura escrita por mujeres en Latinoamérica en el siglo XX. Si bien en la región hubo escritoras anteriores a ella', su obra es la primera que logra una madurez escritural al plasmar de manera compleja e integral un universo ficcional articulado al contexto en el que se produce, dejando sentado un alto derrotero que prácticamente continúa sin ser alcanzado al día de hoy². Moreno escribe desde sus experiencias como miembro de la élite local, con una posición fuertemente crítica frente a la sociedad patriarcal en la que tuvo que crecer, viendo cómo las mujeres son sometidas a altos grados de violencia física y simbólica.

La autora publica su obra narrativa en la segunda mitad del siglo XX, entre 1969 y 1995. Desde un principio la crítica especializada local y nacional se interesa en ella, y con el tiempo llega a ser identificada como una gran escritora. Sin embargo, aún hoy su nombre y sus textos continúan siendo conocidos principalmente en el ámbito académico colombiano y por un limitado número de lectores. Como una muestra de la invisibilización de la que sufre, podemos decir que durante años no fue posible conseguir sus textos en librerías. ${ }^{3}$ Además, por ejemplo, en Colombia ni un solo colegio, teatro, biblioteca, plaza o edificio lleva su nombre; ningún premio literario ha sido creado en su honor, y salvo por esfuerzos de los conocedores de su obra, los aniversarios de sus publicaciones o de su nacimiento y muerte pasan casi desapercibidos.

Una de las causas de la poca divulgación que ha tenido Moreno se encuentra, sin duda, en el hecho de que sea una mujer en el ámbito masculino y masculinista de la literatura. A pesar de haber sido cercana del Grupo de Barranquilla, del Boom y del Postboom, no se han considerado en detalle las relaciones que sus textos sostienen con los de los autores de estos movimientos. No obstante, la crítica que ha pretendido darle a su obra un lugar propio en el campo literario la ubica, por un lado, como un "epígono" de García Márquez, y por otro, como una excepción femenina o "ínsula". ${ }^{4}$ Como explica Michèle Soriano (2013), la norma cognitiva masculina no solo dicta que las mujeres sean excluidas de los campos del saber, sino que en esta exclusión "está en juego la violencia de la prohibición, que engendra otras opresiones: ignorancia, impotencia, privación de libertad, sujeción" (p. 95). En el caso de Moreno, ambas posturas han contribuido a hacerla ver como una escritora al margen, hermana menor o rara avis, lo que finalmente ha impedido que hasta ahora se tracen con claridad los lazos que teje con la tradición de ruptura de la literatura caribeña y la escrita por mujeres.

El presente análisis se enmarca en los estudios sobre la figura del autor que son "actualmente uno de los campos más prolíficos de la teoría literaria, en su cruce con disciplinas como el análisis del discurso o la sociología del arte y la literatura" (Aina PÉREZ; Meri TORRAS, 2015, p. 2). Compartimos el concepto de "figura autorial" como un producto "en sí mismo textual, (es decir, como corpus conformado por un conjunto de textos heterogéneos: biográficos, académicos, visuales, autobiográficos, etc.); como construcción significativa que no se sitúa fuera y antes de la obra en sí sino que (...) constituye uno de los productos del sistema literario" (PÉREZ; TORRAS, 2015, p. 2).

Desde el célebre texto de Roland Barthes (1994) "La muerte del autor", mucho se ha escrito acerca de esta figura. Posteriormente, Michel Foucault (2010) en "¿Qué es un autor?" dio un giro en la comprensión del concepto. De manera más reciente, este campo de estudio ha encontrado un nuevo desarrollo, principalmente desde la sociología de la literatura, el análisis del discurso, y la teoría y crítica feminista, ${ }^{5}$ con autores como Nathalie Heinich, Ruth Amossy, Jérôme Meizoz, José-Luis Díaz y Dominique Mainguenau, entre otros. Una definición desde estos enfoques teórico-críticos la tenemos aquí:

\footnotetext{
' Las precursoras del Caribe colombiano están aún por redescubrirse, y estudios sobre sus obras por hacerse; sin embargo, puede citarse a Priscila Herrera de Núñez (1882-1959), Lydia Bolena (Julia Jimeno de Pertuz) (1882-1959), Amira de la Rosa (1903-1974), Marzia de Lusignan (Juana Sánchez Lafaurie) (1910-¿?), Lilia Senior de Baena (19111992), Olga Salcedo de Medina (1915-1989) y Judith Porto de González (1925-2016).

${ }^{2}$ Lo que no quiere decir que posterior a Moreno no haya habido en el Caribe colombiano narradoras de gran calidad, como Hazel Robinson, Mary Daza Orozco, Lya Sierra, Margarita García Robayo, por citar algunas.

${ }_{3}^{3}$ Su novela En diciembre llegaban las brisas fue reeditada por Alfaguara en el 2014 y los Cuentos completos en el 2018 por Penguin Random House.

${ }^{4}$ Así que no se trata solamente de "corregir" dicha ausencia al "incluir" a Moreno o a otras escritoras en el campo literario, sino que hay que hacer visibles esas normas que las han excluido de manera violenta, pues de lo contrario, el campo literario seguirá operando de la misma manera, sin que se cuestionen las bases mismas de su organización. ${ }^{5}$ Se pueden identificar autoras pioneras como Sandra Gillbert y Susan Gubar, Michelle Coquillat, Joanna Russ, Christine Planté, Peggy Kamuf, Susan Friedman, entre otras, que se interesaron desde fines de los 70 y los 80 por la figura de la autora y la escritura de mujeres.
} 
En el marco de estas perspectivas, el autor/la autora ya no aparece como un sujeto previo a su producción, con la cual establece una relación de control y expresión, sino como un producto cuyo origen ya no es una instancia solitaria y autónoma sino el colectivo de agentes que participan de la cultura entendida como institución y mercado, incluyendo sus receptores o consumidores. (PÉREZ; TORRAS; CRÓQUER, 2015, p. 23)

Ahora bien, Pérez, Torres y Cróquer (2019) introducen el tema de la autoría y el género haciendo una serie de preguntas que tienen que ver con las concepciones falsamente universalizantes del sujeto que prevalecen en el campo literario y artístico. Al hablar de autor, se ha estado hablando en realidad de la autoría en masculino, dado que la creación es una actividad considerada como un privilegio de varones (a las mujeres les corresponde la procreación, la reproducción). Entonces, desde esta evidencia, surgen preguntas como: ¿en qué medida una mujer puede soñarse escritor? ¿Puede reconocerse en esta categoría? ¿Cómo se encarna un escritor en femenino? ¿Cómo se configura la idea y la imagen de la escritora y de la autora? ¿Bajo qué exclusiones, inclusiones, prejuicios, reglas, garantías? Es en esta línea que damos inicio al análisis de la imagen de nuestra autora, Marvel Moreno.

Por su parte, en el artículo "Escritor e imagen de autor", Dominique Mainguenau (2015, p. 18) explica que "la problemática de la imagen de autor se centra en la interacción entre el autor y los diferentes públicos que producen discursos sobre él: críticos, profesores, gran público". Su estudio se centra en la negativa a acatar lo que la teoría literaria estructuralista dictaminó: que la figura "textual" del "narrador" debía separarse de la figura "extratextual" o biográfica (que además se supone anterior al texto) del "escritor". Mainguenau sí hace una distinción entre autor, imagen de autor y escritor, pero también traza los hilos que unen a estas figuras.

Mainguenau aclara que ya Foucault demostró que el concepto de "autor" no se refiere a una simple exterioridad del texto (es decir, el contexto), sino que opera en una suerte de "frontera". Por ello, Foucault prefirió hablar de "función autor", función que sí se relaciona con el nombre del autor, el "propietario" del texto, a quien se le atribuye una obra, ${ }^{6}$ su "responsable; pero además, y mucho más importante, se trata de la figura a la que se le atribuye una determinada postura en un campo discursivo: es "la proyección, en términos siempre más o menos psicologizantes, del tratamiento aplicado a los textos, de los acercamientos realizados, de los rasgos establecidos como pertinentes, de las continuidades admitidas, o de las exclusiones practicadas" (FOUCAULT, 2010, p. 63). Es decir, al autor también se lo construye, teniendo en cuenta los rasgos principales de su estilo, sus temas recurrentes, su valor o calidad escritural, incluso sus contradicciones. En ese sentido, el autor no es nunca el escritor (la persona real o biográfica), como tampoco corresponde directamente al narrador del texto (parlante ficticio). Foucault aclara que el autor se encuentra justamente en la escisión, en el in-between de esas figuras (2010, p. 65).

Volviendo al concepto de imagen del autor propuesto por Mainguenau, este afirma que:

Lo quiera o no, el escritor construye una imagen de sí a través de una multitud de comportamientos verbales o no verbales mediante los cuales muestra lo que es, para él, ser escritor. Pero su imagen de autor efectiva se elabora, por una parte, en la interacción entre esos comportamientos y las obras; y, por otra parte, en la interacción entre esas obras y las reacciones de los públicos. (MAINGUENAU, 2015, p. 23)

Propone entonces que la imagen de autor está compuesta por dos "zonas de activación", estrechamente ligadas: la que concierne al texto, y la que concierne al actor, "cuyo comportamiento se apoya y actúa sobre las representaciones colectivas de lo que es la actividad normal de escritor en un lugar y en un momento dados" (MAINGUENAU, 2015, p. 21). Por cuestiones metodológicas, en este artículo nos ocuparemos a continuación de la primera zona, y más delante de la segunda.

\section{Sobre las narradoras y focalizadoras}

Es común que la imagen del autor, y sobre todo de la autora, se construya asociándola con la de los personajes de la obra, como suerte de dobles o álter ego de la persona que escribe. Asimismo, esta imagen se relaciona - se "contamina" - con la de la figura del enunciador, con el ethos del narrador, sobre todo en los relatos "en primera persona", cuando quien narra es personaje.

En el caso de la obra de Moreno, sus textos están narrados casi en su totalidad por voces femeninas, ya sean narradoras o focalizadoras. La mayoría de las veces (en 18 de sus 27 cuentos), la autora utiliza una voz narrativa, "en tercera persona", fuera de la historia, pero que narra siempre desde el punto de vista de un personaje femenino (en 14 cuentos). Las veces en

\footnotetext{
${ }^{6}$ Como bien se sabe, la discusión del autor se relaciona estrechamente con las cuestiones de la escritura y de la obra, su constitución, continuidad y unidad. En el caso de Marvel Moreno, se conoce que sus textos han pasado por varios lectores y editores, quienes han actuado como albaceas, correctores, recopiladores, modificadores, herederos e incluso censores. Entre los episodios más importantes se encuentra la no publicación de la novela que dejara inédita, El tiempo de las amazonas.
} 
que la autora recurre a la voz narrativa "en primera persona" (9 cuentos), este corresponde a un personaje femenino, quien suele no ser protagonista sino testiga o espectadora de los hechos (7 cuentos). Entonces, podemos afirmar que la obra de Moreno presenta de manera mayoritaria una visión subjetiva y femenina de lo narrado, pero que esta visión se esconde tras una pantalla de objetividad, en primer lugar, bajo la figura de voces narrativas "en tercera persona", y en segundo lugar, bajo la figura de testigas. Esta configuración de las voces enunciantes apunta de manera evidente a la figura de la escritora, alguien observa al mundo, lo analiza y trata de explicar el funcionamiento de la sociedad y las actuaciones de los seres humanos. Ahora veremos de cerca uno de los relatos en primera persona, para tener una mejor idea de lo que estamos hablando.

En el cuento "El espejo", casi la totalidad del relato consiste en la transcripción de una carta, cuyo remitente es Juana de Cebellón, tía de Mario y Marina, gemelos incestuosos. Ella escribe la carta a cierto abogado con el fin de dar su versión de los hechos - la extraña muerte de la esposa de Mario -. El cuento comienza con un "Estimado doctor" seguido de dos puntos: "Con inmensa tristeza me dirijo a usted para hablarle del drama que agobia a nuestra familia y suscita esos infames comentarios en los periódicos de la región. Usted ha aceptado defender a mi sobrino Mario ante los tribunales" (Marvel MORENO, 2018, p. 245). Los y las lectoras nos enteramos del nombre de la remitente de la carta porque al final del cuento aparece una nota aclaratoria entre paréntesis: "(Esta carta fue encontrada entre los papeles dejados al morir por doña Juana de Cebellón. Después del juicio los gemelos viajaron al extranjero y nunca se tuvo noticias de su suerte)" (MORENO, 2018, p. 257).

Esta nota final identifica con nombre y apellido a la voz narrativa de la carta - doña Juana de Cebellón -, pero omite la identidad de su autor o autora, que queda como incógnita. Sin embargo, se puede deducir que se trata de alguien perteneciente a la comunidad, ya que la historia de los gemelos era vox populi: doña Juana hace mención a "esos infames comentarios en los periódicos de la región" (MORENO, 2018, p. 245). El autor o autora de la nota conoce incluso la continuación de la historia: sabe que doña Juana muere y que los gemelos se van del país. Por ello se puede imaginar que se trata de alguien cercano a la familia, que tiene acceso a "Ios papeles dejados al morir por doña Juana" (MORENO, 2018, p. 257). Así, esta voz no es por completo anónima y, al igual que doña Juana, es testigo de los acontecimientos, pudiendo tal vez ser otro pariente más lejano. Y lo que es más llamativo: al exponer la carta, está haciendo público un asunto íntimo que doña Juana quería que permaneciera en secreto. Se trata, pues, de un/a insider que actúa como expositor/a de los problemas de su propia familia.

Entonces, en "El espejo" encontramos dos voces narrativas: doña Juana, autora de la carta, y el autor o autora de la nota. ${ }^{7}$ En ambos casos, se trata de personas que escriben, que toman la pluma para contar lo sucedido, es decir, figuras de escritor/a. Estas cumplen el rol de portavoces de los protagonistas, atreviéndose a contar lo que les sucede a otros; su testimonio constituye una prueba o evidencia de los hechos. Como dijimos antes, es una constante en la narrativa de Moreno que esto suceda, que se tematicen los procesos escriturales. Esta es una de las principales características de la narración de la novela En diciembre llegaban las brisas (MORENO, 1987), en donde al final del libro, uno de los personajes - Lina Insignares - se declara como escritora, y como probable autora de la misma, en un complejo juego metadiegético.

Pasemos ahora a analizar las voces narrativas de uno de los relatos "en tercera persona". "Oriane, tía Oriane" es un cuento de carácter fantástico en el que las sugerencias e insinuaciones abundan, dando margen a un amplio espectro de interpretaciones, por lo que ni la historia misma queda esclarecida. Sin embargo, ofrecemos estos datos: la niña María va de vacaciones a casa de su tía abuela Oriane, quien se ha mantenido marginada de la familia. Poco a poco se va desarrollando una relación de complicidad entre las dos, no exenta de secretos y misterios, entre ellos la relación incestuosa que Oriane pudo tener en el pasado con su hermano Sergio, ahora muerto. Poco a poco María va dejando atrás la infancia. El día antes a su partida tiene una suerte de ensoñación/pesadilla romántico-sexual con una figura, una sombra, que al final se asocia a un hombre desconocido que andaba merodeando y que finalmente había entrado a la casa, según Fidelia, la empleada.

La voz narrativa "en tercera persona" no utiliza un punto de vista general, sino que focaliza desde uno de los personajes, en este caso, María, para quien Oriane es una presencia positiva, aunque enigmática. A lo largo del texto, una María niña/adolescente percibe lo que ocurre, y una María adulta recuerda y narra lo percibido durante esas vacaciones lejanas. Para esa María ya casada, el tiempo "no era más un chispear de instantes sino el lento transcurrir de días iguales" (MORENO, 2018, p. 11). Este elemento tiene, por una parte, el efecto de trasladar la enunciación del relato a un presente de la enunciación en el que lo ocurrido toma la forma de un pasado remoto y borroso; por otra, refuerza la verosimilitud de la historia como una cadena

${ }^{7}$ A esto hay que agregarle que doña Juana no es la directa espectadora de todos los acontecimientos narrados, pues no vive con los gemelos, sino que tiene una "informante": la cocinera Honoria. Doña Juana le confiesa al abogado que le pagaba extra para que se mantuviera allí, espiando. En otras palabras, aunque no se encuentra explícito en el relato, se puede imaginar un tercer nivel de narración: Honoria como narradora. 
rota de sucesos desdibujados, pues se trataría de acontecimientos vividos por esa joven e inocente María, cuya visión es obligatoriamente infantil e imprecisa.

Entonces, a pesar del narrador omnisciente, los y las lectoras tenemos acceso a la información solo a través del prisma de María, quien va entrando poco a poco en el universo axiológico de esa decadente y evasiva tía. La niña se siente envuelta en una sensación de fascinación y a la vez de desconfianza. Sospecha que es ella la autora de unos extraños ruidos que la persiguen por la casa, lo cual la asusta y le encanta al mismo tiempo. Al final del relato, María no desea regresar a casa con su abuela, con quien normalmente vive. Ha desarrollado una complicidad con Oriane que va más allá de las palabras, que se construye por medio de silencios, gestos imperceptibles, sugerencias y adivinanzas. ${ }^{8}$

A medida que el texto sigue su curso, se van manifestando ciertos indicios de lo que pudo ocurrir en el pasado. La voz de Fidelia también interviene: se queja de la presencia de María en la casa, "culpando a su tía de haber despertado lo que para el bien de todos debía dormir, y luego había hecho alusión a algo ocurrido muchos años antes, algo asociado a la muerte de alguien en el mar" (MORENO, 2018, p. 13). En este punto, ya las lectoras pueden adelantar varias hipótesis: Sergio, el fallecido hermano de Oriane y de la abuela de María, ha regresado como fantasma, a repetir la relación incestuosa con la sobrina nieta.

El análisis de las voces en la obra de Moreno nos lleva a entender que el juego que se da entre las diferentes instancias de la narración es el resultado de la complejidad de consciencias femeninas representadas que presentan características similares, entre ellas, el deseo de analizar y entender los acontecimientos, organizarlos de tal manera que tengan algún sentido. Esto remite, sin duda, a la figura de la escritora. Así, los personajes femeninos dejan de ser figuras silenciosas (o silenciadas) y se encargan de rescatar las historias propias o de su entorno femenino, historias que habrían pasado al olvido de no haber sido porque alguna decide convertirse en una portavoz que se atreve a contar lo que otras callan. Surge aquí la figura de la sociología de la literatura del escritor, escritora en este caso, como vocero lúcido de una sociedad.

\section{Judith Shakespeare en París}

La construcción de la imagen de Marvel Moreno como autora se ha edificado sentando sus bases sobre ciertos pilares de su biografía, determinados momentos en su vida, mientras que otros no se mencionan o se les resta importancia. Por ejemplo, se han resaltado las experiencias vividas al interior de cuatro de los grupos sociales de los cuales hizo parte: 1) fue por un periodo una dama de Barranquilla; 2) frecuentó a los miembros del Grupo de Barranquilla; 3) compartió con los intelectuales latinoamericanos en París; 4) y se asocia al grupo de escritoras latinoamericanas con tendencia feminista. No obstante, la imagen que se ha ido construyendo de ella la retrata precisamente como una disidente de esos grupos, como alguien fuera de los campos que debería haber integrado.

Si tomamos en cuenta su historia personal, vemos que hay un largo y constante proceso de desarraigo, que en su caso tiene que ver con la búsqueda de una identidad propia. Marvel Moreno siempre se sintió como una outsider en su medio, y podría ser descrita como una niña mala y una joven rebelde. No obstante, la imagen que se ha construido de ella presenta un giro hacia la mitad de su vida: si bien la rebeldía nunca la abandona como signo característico, prevalece la idea de que desde que se instaló en París, llevó una vida más bien reservada.

En esta ocasión no me referiré a la primera etapa de su vida: su infancia y juventud en Barranquilla, la relación con su madre, su padre y su abuela materna, su participación como reina del Carnaval en 1959, su matrimonio con el periodista y escritor Plinio Mendoza. Me interesa, en cambio, una etapa menos documentada y estudiada: cuando se "convierte" públicamente en escritora, a partir de su salida de Colombia en 1969, cuando tiene treinta años, y su vida en París durante más de dos décadas, hasta su muerte en 1995. En este periodo he identificado principalmente dos imágenes opuestas de la autora, que se presentan de forma paralela: la de la mujer fuerte, independiente, que lo deja todo por ser escritora en París, y la de la mujer frágil, pobre y enferma, escribiendo desde un exilio precario.

A Marvel Moreno la rodea, en primera instancia, la imagen de una persona que asume temerariamente su destino. La crítica colombiana Helena Araújo (1996, p. 126) comenta que la autora era "legendaria entre todas nosotras por haberse atrevido a venir a París en los años setenta dejándolo todo para aprender a ser escritora". Este "nosotras" que utiliza Araújo se refiere a las intelectuales latinoamericanas más jóvenes, que llegaron a París en los ochenta, posterior a Moreno, quien, en ese caso, es una pionera para ellas porque llegó en el 69 solo con la vocación de escribir. 9

${ }^{8}$ Oriane se convierte en una guía para su sobrina nieta, desplegándose una relación de tipo pedagógico entre ellas. En este sentido, "Oriane, tía Oriane" es un texto que puede ser leído como relato de formación.

${ }^{9}$ En Barranquilla, Moreno era alguien relativamente conocida (por sus apellidos, por haber sido reina del Carnaval); tenía una casa, una empresa, estaba estudiando una carrera universitaria (Economía en la Universidad del Atlántico). Llega a Europa con su marido y sus hijas, sin haber terminado sus estudios, sin trabajo, sin hablar francés. 
París es, al igual que Barranquilla, una ciudad ambivalente en la vida y obra de Moreno. Allí la mujer y la escritora van a enfrentarse a sinnúmero de problemas: la pobreza, la enfermedad, la violencia conyugal, el desamor, la soledad. Al mismo tiempo, París le dará la distancia necesaria para escribir sin tapujos acerca de lo vivido hasta entonces, y le proporcionará la experiencia del intelectual y artista en exilio.

Sin duda, París es la ciudad literaria por excelencia, lugar en el que tantos han escrito sus obras. En la entrevista que concedió en 1983, Moreno habla de la efervescencia intelectual de París, efervescencia que, según ella, se encuentra "en ciertas revistas y en la gente que uno conoce. Gente formidable: todo el tiempo pensando, analizando, ensayando, discutiendo" (Ignacio RAMÍREZ; Olga TURRIAGO, 1989, p. 282). Este comentario llama la atención porque en ningún artículo consultado encontramos que se diga que Moreno participó activamente de la agitada vida parisina: no se dice que frecuentara ningún café, ninguna tertulia. Cuando se menciona que era amiga de los intelectuales latinoamericanos en París, este no deja de ser un comentario biográfico que no ha sido llevado a un análisis más profundo acerca de, por ejemplo, su pertenencia a movimientos y corrientes literarias, o la relación de su obra con las de aquellos.

Y sin embargo, ahí estuvo. Moreno tuvo la oportunidad de conocer a muchos escritores del Boom y el Postboom, debido a que participó en la efímera pero significativa revista Libre junto a su esposo entonces, Plinio Mendoza. Libre fue una revista literaria en español que, según Jacques Gilard y Fabio Rodríguez Amaya (1997b, p. 256), aglutinaba "entorno a sí a los escritores latinoamericanos residentes o exiliados en París". Estos críticos afirman que Moreno fue redactora de la revista; como tal, estableció vínculos con Carlos Fuentes, Mario Vargas Llosa, Severo Sarduy, Jorge Edwards, Julio Cortázar, Octavio Paz, Jorge Semprúm, entre otros escritores hombres - bien sabemos que en el Boom no se suele incluir a ninguna mujer -. Al parecer, en medio de todos estos grandes, bendita entre los hombres, estaba Moreno. En otro texto, Gilard (1997, p. 161) aclara entre paréntesis que Moreno nunca apareció oficialmente en los créditos de la revista: "la participación de Marvel Moreno en Libre (donde nunca figuró su nombre, por cierto)". Mendoza nunca ha mencionado este hecho; el único que lo hizo fue el escritor catalán Juan Goytisolo, gestor del proyecto de la revista, quien conoce a Moreno en esta época y se vuelve su gran amigo:

Conocí a Marvel Moreno en 1970 cuando a raíz del audaz proyecto de la revista Libre y la propuesta por García Márquez de su amigo Plinio Mendoza como secretario de la misma, ella y su marido se trasladaron desde Colombia a París. La recuerdo en la fiesta del lanzamiento de la revista (...): una mujer bella y joven con el encanto, la inteligencia y un dejo de exótica languidez de algunas heroínas de Fuentes o Carpentier. A esta impresión inicial de esbeltez y fragilidad se sobrepuso otra imagen: la de la colaboradora enérgica y apasionada de nuestra empresa, la de su profundo y justo sentido crítico de las sociedades iberoamericanas y una valentía y rigor moral muy raros en el mundo de habla hispana. (Juan GOYTISOLO, 1996, p. 137)

El paso de Moreno por Libre no es, pues, oficial: estuvo ahí, pero de ello no queda ninguna constancia, salvo por el testimonio de Goytisolo. En este comentario podemos observar claramente la escisión entre la inicial percepción de Moreno como objeto (bello y exótico) y la posterior, en la que ya parece que se la considera un sujeto, capaz de pensamiento crítico y de agencia.

De la misma manera, con respecto a la pertenencia de Moreno al Grupo de Barranquilla, se admite que la escritora frecuentaba a algunos de sus integrantes, pero nunca se la menciona como "miembro" del Grupo como tal. Esto ya va dando idea del lugar incierto, por no decir inexistente, que ocupa Marvel Moreno en el campo de la producción cultural colombiana y latinoamericana.

Pero así Moreno no fuera una figura central del mundo intelectual, sí fue testigo y partícipe de él. Estaba dentro, pero se mantuvo al margen y observó: en cada velada a la que era invitada por sus amigos latinoamericanos y latinoamericanistas, en cada lanzamiento de sus libros o de libros de conocidos, inauguración de exposiciones de amigos pintores, reuniones íntimas en su casa. Probablemente a medida que su salud iba empeorando ${ }^{10}$ se fue alejando más y más, hasta que de ella solo quedó la imagen de la mujer que escribe encerrada en

Por un lado, hay un movimiento del centro al margen: en Barranquilla, Moreno pertenecía a la clase pudiente, ella era "alguien"; en París, en cambio, pasa a ser "nadie": una pobre inmigrante que ni siquiera tendría cómo curarse. En todo caso, París es para ella un exilio tanto de su país como de su clase. Por otro lado, Barranquilla es la provincia, la periferia; París, la gran urbe, la ciudad luz, un eje artístico e intelectual. Habría que conectar esta situación de precariedad con los conceptos de exilio, expatriación, o con el más actual de migración, sobre todo en lo que tiene que ver con la población femenina. La migración se entiende como un fenómeno cíclico o permanente en el que la población parte "voluntariamente" de su región de origen, ya sea dentro del mismo país o al exterior. Las causas pueden ser políticas, socioeconómicas o personales. Efectivamente, podríamos referirnos a Moreno con los términos más contemporáneos de inmigrante, sobre todo porque los fenómenos recientes de las migraciones internacionales sur-norte y este-oeste a gran escala han hecho más visible la difícil situación, a menudo sometida a la violencia, de la mujer migrante. Este tipo de estudio queda por hacerse.

${ }^{10}$ Moreno se enferma a principio de los 70 , es diagnosticada más adelante con Lupus, enfermedad que la debilita grandemente por épocas, y finalmente muere de un enfisema pulmonar en 1995. 
su habitación, a room of one's own. Así la describe una amiga suya, Cecilia Díaz (1996, p. 132): "No puedo disociar mi imagen de Marvel de la penumbra y del silencio... Consagrada a escribir, casi aislada del mundo, exilio en el exilio para poner sobre el tapete la ciudad de sus pesadillas". Salta a la vista lo opuesto de este testimonio al de Goytisolo, en sus primeros años en París, antes de las penurias económicas, intelectuales, afectivas y de salud.

La imagen de la escritora aislada y, hasta cierto punto, fracasada en lo que tiene que ver con el reconocimiento público de su labor, remite a la figura imaginada por Virginia Woolf de Judith Shakespeare, la hipotética hermana de Shakespeare, es decir, de un posible Shakespeare en cuerpo de mujer. En Un cuarto propio, Woolf describe lo que hubiera podido ser la vida de alguien con el talento del poeta y dramaturgo inglés de haber sido una mujer:

Cualquier mujer nacida en el siglo dieciséis con un gran talento se hubiera vuelto loca, se hubiera suicidado o hubiera acabado sus días en alguna casa solitaria en las afueras del pueblo, medio bruja, medio hechicera, objeto de temor y burlas. Porque no se necesita ser un gran psicólogo para estar seguro de que una muchacha muy dotada que hubiera tratado de usar su talento para la poesía hubiera tropezado con tanta frustración, de que la demás gente le hubiera creado tantas dificultades y la hubieran torturado y desgarrado de tal modo sus propios instintos contrarios, que hubiera perdido la salud y la razón. (...) Y, sin duda alguna, pensé mirando los estantes en que no había ninguna obra de teatro escrita por una mujer, no hubiera firmado sus obras. (...) Un residuo del sentido de castidad es lo que dictó la anonimidad a las mujeres hasta fecha muy tardía del siglo diecinueve. (...) la publicidad en las mujeres es detestable. (Virginia WOOLF, 2008, p. 37-38)

A pesar de la distancia histórica y cultural que separa a Judith Shakespeare de Marvel Moreno, París y el muy emancipado siglo XX no fueron muy generosos con la colombiana: casi interna en un hospital psiquiátrico, aislada en su apartamento, depresiva hasta el intento de suicidio. En un homenaje al poco tiempo de su muerte, Fabio Rodríguez Amaya, crítico literario y amigo de la autora, describe así su situación:

Casi nadie te tomó en serio cuando nos entregaste tus primeros cuentos escritos con caligrafía de adulta y corazón de niña. Te negaron el derecho a convertirte en escritora: por miedo Marvel, por envidia Marvel, por rencor Marvel, porque eras más y mejor escritora que miles de escribanos congregados bajo rótulos de la oficialidad. (RODRÍGUEZ AMAYA, 1996, p. 145)

En efecto, el primer libro de cuentos de Moreno - Algo tan feo en la vida de una señora bien (MORENO, 1980) - pasó prácticamente desapercibido para el público y la crítica y, más adelante, su novela y su segundo libro de cuentos - En diciembre llegaban las brisas (MORENO, 1987) y El encuentro y otros relatos (MORENO, 1992) - no recibieron (ni han recibido, a mi juicio) la atención que merecían. La sociología de la literatura nos enseña que una obra no surge solo por su calidad estética sino gracias a una serie de factores de la gran maquinaria literaria: publicistas, editores, periodistas, crítica literaria especializada, todo se conjuga para que un libro o un autor sean reconocidos. Es un hecho que la obra de Moreno tuvo un recorrido bastante difícil en el que jugó un papel importante - si no fundamental - el carácter "reservado" de Marvel Moreno del que se habla una y otra vez en los textos que la describen.

\section{¿Escritora reservada o artista maldita?}

Casi todos los que conocieron a Marvel Moreno mencionan su "recatada personalidad". Por ejemplo, Goytisolo (1987, p. 16) la describe como "vulnerable, aislada, obligada a expatriarse con sus heridas y cicatrices morales, pero libre al fin en su refugio parisiense". Rodríguez Amaya (1997, p. 179) dice que era "un personaje que condujo una vida discreta, oscilante entre el pudor, la sencillez y el aislamiento en el plano personal".

Para ejemplificar ese "aislamiento" y "pudor", sirva que contemos cómo se dieron sus primeras publicaciones. Gilard cuenta que ella nunca quiso publicar y que todo sucedió sin que su voluntad interviniera. En 1969, estado aún en Colombia, ella "casualmente" se encuentra con Germán Vargas, periodista barranquillero, y "por coincidencia" tenía en su bolso su primer cuento, "El muñeco". Por intermedio de Vargas, el cuento se publica ese año en la revista Eco y en el Magazín dominical de El Espectador. Más adelante, ya en París, Moreno conoce a Gilard quien, siendo un profesor latinoamericanista entusiasta de la obra de García Márquez, frecuentaba a Plinio Mendoza, amigo del escritor colombiano y esposo de Moreno. Es Mendoza quien le entrega a Gilard (1997, pp. 11-13) un cuento escrito por su esposa; Gilard acota: "supongo que después de quitárselo casi a la fuerza".

Ahora bien, parece improbable que tanto pudor viniera de una mujer que había desafiado las normas del mundo al cual pertenecía; recordemos que Moreno fue reina intelectual del carnaval, traidora de su clase por haberse casado con un hombre de otra región del país ${ }^{11}$, pobre

"En Colombia existe una proverbial querella entre las gentes del "interior" del país, los "cachacos", y los del Caribe, los costeños. Para una costeña "de alcurnia" como Moreno, casarse con un "cachaco" era un desafío a las normas 
e izquierdista, madre y primera mujer admitida en el programa de Economía de la Universidad del Atlántico, y dueña de una empresa de mercadeo y publicidad. Sin embargo, parece que una vez que comienza a escribir de manera sistemática, Moreno pierde interés por los demás retos y se concentra en la escritura. No gasta sus energías en una militancia políticamente activa (feminista o izquierdista), ni tampoco en una carrera propagandística de su obra.

Con respecto a su vida en París, por un lado, Moreno no siguió, como Mendoza o García Márquez en sus inicios, una carrera periodística, aunque parece que tuvo coqueteos con este género. La autora realizó cuatro entrevistas, tres de ellas a escritores latinoamericanos - Severo Sarduy, Juan Goytisolo y Carlos Fuentes - publicadas en 1973 en El Nacional de Caracas, y una al modisto Pierre Cardin. La historia detrás de estas entrevistas queda aún por develarse. Por otro lado, Moreno no siguió una carrera diplomática a pesar de tener las credenciales para entrar en el medio: provenía de una "buena familia" y estuvo en un momento de su vida relativamente cerca a los círculos del poder: su esposo en ese entonces fue agregado cultural en París y ambos fueron cercanos a los presidentes Julio César Turbay Ayala (1978-1982) y Belisario Betancur (1982-1986). No obstante, luego de publicar sus libros, sobre todo al ser merecedora de algunos premios, ${ }^{12}$ el gobierno colombiano no le ofreció ningún puesto, como podría haber sido. Gilard y Rodríguez Amaya afirman que ella era

(...) hostil a la «lagartería» ${ }^{33}$, detestaba figurar y nada le era más ajeno que la auto promoción. (...) no se puede decir que (...) haya participado en la vida de los intelectuales latinoamericanos de París. Bastan los dedos de una mano para contar los actos públicos en que participó como escritora. (GILARD; RODRÍGUEZ AMAYA, 1997a, p. 11)

Siempre me pareció que esta imagen de "escritora aislada" no correspondía tanto a la realidad como a la imagen que la misma Moreno y que los otros querían forjar de ella. En el mismo texto de Gilard y Rodríguez Amaya (1997a) anteriormente citado se lee:

Salvo sus contactos iniciales, en los años 60, con un muy dinámico grupo de intelectuales y artistas de Barranquilla, su ciudad nativa (entre ellos el crítico Germán Vargas, el novelista Álvaro Cepeda Samudio y el pintor Alejandro Obregón), y los amigos de su primer esposo, Plinio Mendoza (entre ellos García Márquez, también vinculado al grupo de Barranquilla), y salvo su discreta participación en las actividades y los debates de la importante pero efímera revista Libre (París 1971-1972), Marvel Moreno prácticamente no tuvo vida pública (...). Colombiana voluntariamente emigrada, ajena en un primer tiempo a la vida de capillas de su propio país y siempre, más adelante, indiferente a una integración en alguna de esas capillas, y luego prácticamente desvinculada de la vida latinoamericana en París. (GILARD; RODRÍGUEZ AMAYA, 1997a, p. 10-11).

Aquí se está afirmando que Moreno "prácticamente no tuvo vida pública", salvo sus contactos con el Grupo de Barranquilla y el grupo de intelectuales latinoamericanos en París. Pero cualquiera puede ver que esto representa mucha más vida pública que la que llevaron otros tantos escritores cuya imagen no es la de ser "reservados".

No estamos afirmando que Moreno haya sido una suerte de Simone de Beauvoir, Virginia Woolf o de Rosario Castellanos (para citar un caso latinoamericano): escritoras que se movían ampliamente en los círculos intelectuales de su época y región. Lo que queremos decir es que, si se miran desde otra óptica, los hechos pueden desmentir la imagen "reservada" de Moreno. Esa imagen está construida siguiendo un interés: el de hacer verla como alguien desinteresado. Como lo explica Pierre Bourdieu (1998, pp. 353-354), el campo literario es un mundo en el que los agentes pretendientes que quieren ingresar en él deben precisamente mostrar su desinterés para pertenecer a él. Así, hay un afán por afianzar la imagen de Moreno como un agente autónomo, que no tenía otro afán que el arte en sí: los otros campos del poder (el político, el económico, el social) le eran indiferentes. Se afirma, pues, que si bien ella bien hubiera podido integrar esas "capillas", nacionales o internacionales, simplemente no le interesaba: fue su decisión el haber permanecido al margen.

Esta actitud de desinterés en su promoción personal hace parte de la explicación que se da al hecho de que su obra sea tan poco conocida. Pero precisamente el poco "éxito" que tuvo se puede convertir en una señal de que se trata de una gran artista, de una "artista maldita", como parece exponer este párrafo:

Desconocida por el gran público, ignorada por los medios de comunicación, tergiversada por los editores, envidiada y censurada por la cultura oficial y de régimen, objeto del altanero esnobismo incluso de sus compatriotas famosos, hostilizada por la familia, aislada por la

sociales de la élite local.

${ }^{12}$ Con En diciembre llegaban las brisas, fue finalista del premio de novela Plaza y Janés y ganó el premio GrinzaneCavour al mejor libro extranjero en Italia; la película Oriana de Fina Torres, inspirada en el cuento "Oriane, tía Oriane", se llevó el Cámara de oro en Cannes.

13 "Lagarto" es quien busca un puesto, sin merecerlo, por intermedio de sus conocidos. 
enfermedad, asediada por la pobreza, con estos, para nada pocos obstáculos, suscita estupor que haya logrado publicar tres libros en vida. (GILARD; RODRÍGUEZ AMAYA, 1997a, p. 9)

La categoría del poeta o artista maldito ha sido utilizada desde Verlaine, como lo explica Pascal Brisette (2014), para referirse a diferentes periodos y contextos culturales. Se entiende, grosso modo, que se trata de

Creadores superiores abatidos por la desgracia. Sufrieron (o, a través de sus escritos, hicieron creer que habían sufrido) la pobreza; el exilio; la locura; el desprecio de sus pares, de la crítica o del público burgués; la persecución de la lglesia, de las autoridades civiles o de los medios. (BRISETTE, 2014, p. 131) $)^{14}$

Este mito de la maldición literaria se convierte en "mecanismo de legitimación de primera importancia al transvalorar los signos del fracaso y del éxito social y al hacer de la pobreza, de la exclusión y de la persecución las marcas irrefutables del genio" (BRISETTE, 2014, p. 136). Así pues, el mérito intelectual, e incluso moral, de Moreno se comprueba debido a las desgracias y persecuciones suscitadas por la envidia de su medio. El sufrimiento es una bienaventuranza para quien, como ella, lo supo convertir en arte.

Ya lo dice Rosario Castellanos (1972) en su poema "Meditación en el umbral": existe una gran recurrencia de la figuración de las autoras como víctimas de un sino trágico, asunto que se mezcla con la fatalidad que acompaña a una larga lista de personajes femeninos desdichados. Mucho se ha anotado en las biografías de escritoras como Sor Juana Inés de la Cruz, Virginia Woolf, Julia de Burgos, Delmira Agustini, Alfonsina Storni, Alejandra Pizarnik, Silvia Plath o Anne Sexton, solo por citar a algunas de las más representativas. Sin embargo, hace falta un análisis más detallado desde una perspectiva feminista y de género, para encontrar los hilos psicosociales, históricos y culturales que se trenzan para que un destino adverso acompañe a autoras de distintas épocas y lugares. Quizás el estudio que más se acerca es La petite sœur de Balzac de Christine Planté (1989), como veremos enseguida.

\section{La "hermana menor"}

La académica francesa Christine Planté (1989, p. 131) acuña el término de la "hermana menor de Balzac" - la petite sœur de Balzac-para referirse a la situación de subordinación en la que se encuentran las mujeres en el campo literario. ${ }^{15}$ Planté comenta que usualmente se utiliza como justificación de la incursión de las mujeres escritoras al mundo de las letras el hecho de lleguen a él por intermedio de los hombres. A los hombres les resulta "tranquilizador" pensar que ellas tuvieron necesidad de ser iniciadas en ese mundo ajeno a ellas, que debieron ser autorizadas por ellos como instancia superior o competente que, al mismo tiempo, era cercana a ellas afectivamente (PLANTÉ, 1989, p. 132-133). Para citar un caso latinoamericano, la argentina Beatriz Sarlo (1990, p. 79) cuenta que los primeros libros de Norah Lange, Victoria Ocampo y Alfonsina Storni fueron prologados por hombres (Borges, Ortega y Gasset y Juan Julián Lastra, respectivamente). Sarlo habla de las "relaciones erótico-literarias" que había entre este grupo de intelectuales argentinos, en donde el hombre-amante-amado era además un promotor de las escritoras.

No pretendo negar que el influjo que Moreno recibió por parte de hombres fue decisivo en su carrera literaria: desde el padre que la inicia en la lectura, pasando por su matrimonio con un periodista escritor, hasta sus amistades masculinas que la respaldan para que publique y que construyen la legitimación de su obra. Su primer libro de cuentos, Algo tan feo en la vida de una señora bien (1980) va acompañado de un prólogo de Goytisolo y de una presentación de Gilard que inscribe la obra, aunque de manera problemática, dentro de la tradición de escritores costeños, del Grupo de Barranquilla (José Félix Fuenmayor, Álvaro Cepeda Samudio, Gabriel García Márquez). Así que, siendo una obra escrita por una mujer, que trata fundamentalmente acerca de la situación de las mujeres, la mayoría de los que la legitiman son hombres.

No obstante, me interesa resaltar que Moreno también recibió una influencia femenina en su carrera literaria: su abuela en su infancia, y luego las mujeres - académicas y otras escritoras - que la apoyaron en su labor escritural. A pesar de que un estudio más amplio sobre este aspecto urge por ser realizado, puedo aportar algunos datos sobre esto último. Con respecto a las lecturas de mujeres escritoras, aunque no se sabe si Moreno había leído a las precursoras latinoamericanas, sí conocía a algunas contemporáneas suyas, como Rosario Ferré y las pocas que colaboraron en Libre, como Nélida Piñón, Claribel Alegría y Blanca Varela. ${ }^{16}$ Sus referencias

\footnotetext{
${ }^{14}$ Más adelante Brisette menciona también enfermedades como la tisis o tuberculosis, la melancolía o depresión y otro tipo de enfermedades mentales.

15 El término "petite sœur" se ha traducido como "hermana menor". En su origen, se refiere efectivamente a la hermana menor de Balzac, Laure Balzac (posteriormente Laure Suville), escritora francesa. Sin embargo, Planté desarrolla su propuesta sirviéndose de su plurisignificación, que remite a la edad, pero también a la importancia y jerarquía, en oposición al "gran hermano" o "grand frère".

${ }^{16}$ En el primer número de la revista se encuentran, en medio de una cincuentena de colaboradores, dos mujeres: Claribel Alegría y Susan Sontag. En el cuarto y último número aparecen Nélida Piñón y Marta Traba. Este número
} 
del genio femenino eran principalmente europeas y estadounidenses: Simone de Beauvoir, Virginia Woolf, Carson MacCullers y Katherine Mansfield. Con respecto a la escritura de mujeres en Colombia, seguramente conocía, por lo menos de nombre, a la precursora barranquillera Amira De la Rosa y probablemente a Meira Delmar; también sabía de la existencia de escritoras contemporáneas, pues algunas de ellas eran sus amigas o conocidas, como Helena Araújo.

Con respecto al género novela, antes de 1987 - año de la publicación de En diciembre llegaban las brisas -, ya se habían editado en Colombia ${ }^{17}$ y Latinoamérica grandes novelas escritas por mujeres. Se desconoce si Moreno había leído estas obras, pero por lo menos sabemos que desde principios de los años setenta, gracias a su participación en Libre, tuvo algún conocimiento de las letras femeninas latinoamericanas. Más adelante, Moreno participó en algunos encuentros organizados por la Maison d'Amérique latine en París. Helena Araújo (1996, p. 126) dice haberla conocido allí a principio de los ochenta y cuenta que Moreno presentó su libro La Sherezada criolla: "Esa noche (...) pudo hablar en el foro sobre temas que la concernían profundamente: la problemática de la mujer como producción de un sistema de escritura, su opresión en una sociedad machista y clasista".

Considero esta cita de vital importancia pues prueba que la barranquillera sí se interesaba en la temática feminista y que fue también respaldada por un círculo de mujeres intelectuales en su carrera como escritora. Si bien su obra tuvo primero "grandes hermanos", asimismo tuvo "hermanas" que la apoyaron y se solidarizaron con ella. Como dije, lamentablemente se tienen pocos datos acerca de la relación que forjara con ellas, pues en la bibliografía crítica hasta ahora se ha hecho énfasis en su conexión con intelectuales hombres.

\section{La sombra de Marvel Moreno}

La identidad de Moreno como escritora se mantuvo oculta, aun si este hecho estuvo ligado a su deseo por permanecer independiente. Al respecto, Planté (1989, p. 289) propone que muchas veces las mujeres autoras se mantienen "en la sombra" porque ser autora, o querer ser autora, genera en ellas grandes tensiones que intentan aligerar recurriendo a ciertas estrategias de evasión. El miedo producido por las consecuencias negativas que podría acarrear la carrera literaria las puede llevar a dejar definitivamente la escritura y a aferrarse a la existencia ordinaria como tabla de salvación, sobre todo en caso de fracaso. Si bien Moreno sí asumió su labor de escritura a fondo, evitó promocionar su obra. ¿Sería su reserva una reacción al miedo de jugárselo todo como autora? Vemos pues que resulta problemático analizar su postura con respecto al papel del escritor o de la escritora. Pero sin duda, el hecho de reproducir el papel de la "escritora reservada" en gran parte anuló el capital simbólico del que hubiera podido gozar.

Con esta reflexión esperamos haber colaborado en la labor de la crítica feminista de inscribir a escritoras como Moreno en la genealogía de autoras colombianas y latinoamericanas. Aunque estudios más profundos quedan por hacerse, aquí se ha intentado restituir una visión más amplia y compleja de la imagen de Marvel Moreno como autora. Esta visión busca dejar de verla como excepción y, en cambio, trazar las conexiones de su obra con escritoras y artistas precedentes, contemporáneas y posteriores. Solo de esta manera se podrán crear "modelos autoriales a partir de los cuales otras mujeres puedan imaginarse y (re)presentarse como escritoras, añadiendo a la escasez de referentes el hecho de que los existentes aparecen inapropiables o inimitables" (Aina PÉREZ, 2017, p. 147). Así, las nuevas generaciones podrán reconocerse en Moreno y, al mismo tiempo, se podrá repensar la categoría transgresora de la autoría en femenino.

\section{Referencias}

ARAÚJO, Helena. "Se nos fue Marvel". Caravelle. Cahiers du monde hispanique et luso-bresilien, Toulouse, n. 66, p. 125-127, 1996.

BARTHES, Roland. "La muerte del autor". In: El susurro del lenguaje. Más allá de la palabra y de la escritura. Barcelona: Paidós. p. 65-71. 1994 [1984].

BOURDIEU, Pierre. Les règles de l'art. Genèse et structure du champ littéraire. París: Editions du Seuil, 1998.

BRISETTE, Pascal. "Poeta desdichado, poeta maldito, maldición literaria. Hipótesis de investigación sobre el origen del mito". In: ZAPATA, Juan (Comp.). La invención del autor. Nuevas aproximaciones

incluye un dossier titulado "Debate: La liberación de la mujer". En este dossier, seis mujeres intelectuales responden a diez preguntas sobre el tema de la liberación femenina: Rosana Rossanda, Susan Sontag, Marta Lynch, Françoise Giroud, Blanca Varela y Jean Franco. No está consignado si Moreno tuvo alguna relación con estas escritoras.

17 Entre ellas las novelas de Elisa Mujica, de las barranquilleras Fanny Buitrago y Olga Salcedo, de Rocío Vélez de Piedrahita, de Albalucía Ángel y de Helena Araújo. 
al estudio sociológico y discursivo de la figura autorial. Medellín: Universidad de Antioquia, 2014. p. 131-157.

CASTELLANOS, Rosario. Poesía no eres tú: obra poética, 1948-1971. México: Fondo de Cultura Económica, 1972.

DÍAZ, Cecilia. "Marvel para siempre". Caravelle. Cahiers du monde hispanique et luso-bresilien, Toulouse, n. 66, p. 131-132, 1996.

FOUCAULT, Michel. ¿Qué es un autor? Buenos Aires: Ediciones literales, 2010 (1969].

GILARD, Jacques. "Las tres casas de Marvel Moreno". Huellas, Barranquilla, n. 47-48, p. 10-20, 1997.

GILARD, Jacques; RODRÍGUEZ AMAYA, Fabio. "Introducción”. In: GILARD Jacques; Rodríguez Amaya (Comps.). La obra de Marvel Moreno: Actas del coloquio internacional de Toulouse, 3-5 de abril de 1997. Viareggio: Mauro Baroni, 1997a. p. 9-18.

GILARD, Jacques; RODRÍGUEZ AMAYA, Fabio. "Notas para una biografía". In: GILARD, Jacques; RODRÍGUEZ AMAYA, Fabio (Comps.). La obra de Marvel Moreno: Actas del coloquio internacional de Toulouse, 3-5 de abril de 1997. Viareggio: Mauro Baroni, 1997b. p. 255-258.

GOYTISOLO, Juan. "Retrato de una implacable guerra entre los sexos". Diners, Bogotá, p. 52-53, junio $20,1987$.

GOYTISOLO, Juan. "Semblanza a Marvel Moreno". Caravelle. Cahiers du monde hispanique et Iuso-bresilien, Toulouse, n. 66, p. 137-138, 1996.

MAINGUENAU, Dominique. "Escritor e imagen de autor". Tropelías. Revista de Teoría de la Literatura y Literatura Comparada, Zaragoza, n. 24, p. 17-30, 2015.

MORENO, Marvel. Algo tan feo en la vida de una señora bien. Bogotá: Pluma, 1980.

MORENO, Marvel. Cuentos completos. Bogotá: Alfaguara, 2018.

MORENO, Marvel. El encuentro y otros relatos. Bogotá: El Áncora Editores, 1992.

MORENO, Marvel. En diciembre llegaban las brisas. Bogotá: Plaza y Janés. 1987.

PÉREZ, Aina. Un común singular. Lecturas teóricas de la autoría literaria [Tesis doctoral]. Barcelona: Universidad Autónoma de Barcelona, 2017.

PÉREZ, Aina; TORRAS, Meri; CRÓQUER, Eleonora. "Ninguna voz es transparente. Autorías de mujeres para un corpus visibiliza”. Revista Nuevo Mundo. Autoría y género, Barcelona, n. 16, p. 15-27, 2015.

PÉREZ, Aina; TORRAS, Meri. "La autoría a debate: textualización del cuerpo-corpus (una introducción teórica)". Tropelías. Revista de Teoría de la literatura y Literatura comparada, Zaragoza, n. 24, p. 1-16, 2015.

PLANTÉ, Christine. La petite sœur de Balzac. París: Éditions de Seuil, 1989.

RAMÍREZ, Ignacio; TURRIAGO, Olga. Hombres de palabras. Bogotá: Cosmos, 1989.

RODRÍGUEZ AMAYA, Fabio. "La bruja. Homenaje a Marvel Moreno". Caravelle. Cahiers du monde hispanique et luso-bresilien, Toulouse, n. 66, p. 144-145, 1996.

RODRÍGUEZ AMAYA, Fabio. "Una obra maestra de relojería literaria". In: GILARD, Jacques; RODRÍGUEZ AMAYA, Fabio (Comps.). La obra de Marvel Moreno: Actas del coloquio internacional de Toulouse, 3-5 de abril de 1997. Viareggio: Mauro Baroni, 1997. p. 167-179.

SARLO, Beatriz. "Decir y no decir: Erotismo y represión en tres escritoras argentinas". In: BERENGUER, Carmen et al. (Eds.). Escribir en los bordes. Congreso Internacional de Literatura Femenina Latinoamericana, 1987. Santiago: Cuarto Propio, 1990. p. 79-105.

SORIANO, Michèle. "Cuestionamientos actuales de una norma cognitiva: género y discurso literario latinoamericano". In: GARCÍA, Rodrigo; QUIJANO, Mónica; FENOGLIO, Irene (Coords.). La tradición teórico-crítica en Hispanoamérica. Mapas y perspectivas. México: Bonilla-Artigas/ Universidad Veracruzana/UNAM, 2013. p. 93-115. 
WOOLF, Virginia. Un cuarto propio. Barcelona: Seix Barral, 2008.

Mercedes Ortega González-Rubio (mercedesortega@uninorte.edu.co) Doctora en Estudios lberoamericanos de la Universidad de Toulouse. Profesora de la Universidad del Norte, miembro del Grupo Studia de esta institución. Sus áreas de interés son los Estudios feministas y de Género en la literatura y cultura latinoamericana y del Caribe. Entre sus publicaciones más recientes se encuentra el libro Cartografía de lo femenino en la obra de Marvel Moreno (2019), y el artículo "Antagonismo y sororidad en dos cuentos del Caribe hispano" (2018).

\section{COMO CITAR ESTE ARTÍCULO, DE ACUERDO CON LAS NORMAS DE LA REVISTA}

GONZÁLEZ-RUBIO, Mercedes Ortega. "Un lugar en el campo literario: Marvel Moreno como la "escritora reservada"”. Revista Estudos Feministas, Florianópolis, v. 29, n. 2, e66142, 2021.

\section{CONTRIBUCIÓN DE AUTORÍA}

No se aplica.

\section{FINANCIACIÓN}

No se aplica.

\section{CONSENTIMIENTO DE USO DE IMAGEN}

No se aplica.

\section{APROBACIÓN DE COMITÉ DE ÉTICA EN INVESTIGACIÓN}

No se aplica.

\section{CONFLICTO DE INTERESES}

No se aplica.

\section{LICENCIA DE USO}

Este artículo tiene la licencia Creative Commons License CC-BY 4.0 International. Con esta licencia puedes compartir, adaptar, crear para cualquier finalidad, siempre y cuando cedas la autoría de la obra.

\section{HISTORIAL}

Recibido el 08/07/2019

Presentado nuevamente el 02/03/2021

Aprobado el 13/05/2021 